\title{
Digitalización del libro en México. Confrontaciones simbólicas entre alumnosy profesores
}

\section{POR ARMANDO SILVESTRE MONZÓN NIEVES}

armandopsam@gmail.com Universidad Tecnológica Latinoamericana en Línea (UTEL), México.

Fecha de recepción: 19/09/2016

Fecha de aceptación: 21/10/2016

\section{RESUMEN}

En un futuro próximo, los dispositivos electrónicos ocuparán un lugar determinante en las aulas de las escuelas privadas de educación básica. Pero el presente sugiere que la mayoría de los profesores se resiste a la incorporación de recursos digitales a su dinámica escolar, mientras que los alumnos, en su calidad de nativos digitales, manejan con facilidad y comodidad dichos recursos. El gran obstáculo al que se enfrenta la educación privada en México es un problema de mediatización, donde los nuevos dispositivos tecnológicos en lugar de reconfigurar el papel de docentes y alumnos en el proceso discursivo de aprendizaje, pareciera que lo han desconfigurado. El propósito del presente trabajo será explicar cuáles son las confrontaciones simbólicas entre alumnos y profesores a partir de la comprensión semiótica de los recursos digitales. Para ello, es necesario concebir el recurso digital como una metáfora, después como un juego y, finalmente, como una relación donde los estudiantes interactúan con un sistema de signos que tiene una organización discursiva propia, distinta del libro de texto impreso, y desdela cual se construye una nueva narrativa didáctica.

PALABRAS CLAVE: libro de texto, recurso digital, metáfora, juego, discurso.

\section{ABSTRACT}

In the near future, electronic devices will have a central place in the classrooms of the private schools of basic education. But the present suggests that the majority of teachers are reluctant to include digital resources to their school dynamics, while students, as 
digital natives, handle with ease and comfort those resources. The major obstacle facing the private education in Mexico is a problem of media coverage, where new technological devices instead of reconfiguring the role of teachers and students in the discursive process of learning, it seems that it has become disconfigured. The purpose of this work will be to explain what are the symbolic confrontations between students and teachers from understanding semiotics of the digital resources. For this it is necessary to devise the digital resource as a metaphor, then as a game, and finally as a relationship where students interact with a system of signs that has a particular discursive arrangement, different from the printed textbook, and from which constructs a new narrative didactics.

KEYWORDS: textbook, digital resource, metaphor, game, speech.

\section{A MODO DE PRESENTACIÓN}

Un invitado inesperado provoca que su cuerpo transpire más de lo normal. Frota sus manos discretamente antes de saludarlo pero el sudor ya le ha jugado una mala pasada: la palma del otro ha sido humedecida en el intercambio de cortesías. Hilda se siente incómoda, trata de sonreír como todoslo hacen a sualrededor, de manera genuina y espontánea: jóvenes adolescentes emocionados porque tienen en su manos una tableta que ven como un típico juguete nuevo pero que en realidad fungirá como herramienta para complementar sus estrategias de aprendizaje, y un directivo que confía en que las nuevas tecnologías incrementarán el nivel educativo de la casa de estudios que tiene a su cargo y que reposicionarán el prestigio de una de las mejores escuelas privadas a nivel básico que hay en México.

Hilda es profesora de segundo grado de secundaria en la Ciudad de México (octavo grado de educación básica). Tiene 48 años, más de la mitad de su vida dedicada a la docencia a nivel básico. Diversos reconocimientos oficiales y afectivos por parte de sus alumnos muestran que es una profesora capaz. Su vasta experiencia le ha permitido impartir clases de ciencias naturales, ciencias sociales, lengua y matemáticas por igual, lo que le brinda una versatilidad pedagógica que pocos pueden presumir.

En su aula de toda la vida, Hilda se siente orgullosa de sus herramientas de trabajo: un inmenso globo terráqueo, esquemas del cuerpo humano que ella misma construyó con diversos materiales como plástico y madera, decenas de videos y documentales educativos, y un librero que conjuga prestigiosas enciclopedias, atlas, diccionarios y libros de texto (un par de ellos, de su autoría) para conformar uno de los acervos más completos y selectos.

Pero hoy Hilda siente que todo esto deberá cubrirse del polvo y ocultarse en un lugar recóndito para evitar las severas burlas que la tecnología se encargará de construir. Hilda piensa que sus herramientas para impartir clase serán sustituidas por una delgada y pequeña pantalla de $20 \times 13 \mathrm{~cm}$. Y 
aunque las apocalípticas suposiciones de Hilda no se volverán realidad en los próximos días, ella sabe que no está preparada para conducir su clase a través de una tableta electrónica, ya que apenas puede manejar un teléfono inteligente.

A pocos kilómetros de distancia de la escuela secundaria de Hilda, un gerente editorial también está preocupado porque la implementación del nuevo proyecto educativo no ha tenidola recepción esperada y ahora necesita planear una estrategia que permita su consolidación, ya que en un principio se creyó que sería el parteaguas que sanaría las finanzas de la editorial más grande de habla hispana, todavía afectada por la profunda crisis que colapsó a España a finales de la década pasada.

El gerente editorial se reúne con sus editores y sus asesores pedagógicos, quienes exponen larga y detalladamente el problema: centenares de profesores evitan a toda costa el uso de los nuevos recursos digitales creados por la editorial, tal y como Hilda lo hará en los próximos días. La razón, una mediatización que es bien conocida por los nativos digitales o educandos, es relativamente desconocida por los profesores, quienes temen perder el cauce de su clase y verse rebasados en el manejo del dispositivo y de la información. Aunque en más de una ocasión los asesores pedagógicos brindarán capacitaciones sobre el uso de los dispositivos y el funcionamiento de los recursos digitales, lo cierto es que prevalecerá un entorno de incomodidad por parte de los profesores.

La problemática anteriormente descrita es una arista más de la compleja discusión del estado dela educación en México. Prácticamente en todo el mundo se sabe que la relación entre el gobierno y la docencia ha sido especialmente truculenta en el presente mandato de Enrique Peña Nieto, y que dicha relación se aboca, principalmente, al problema de la educación pública en los sectores más marginados del país.

Caso contrario, la educación privada pareciera que goza de un buen estado de salud. De acuerdo con el censo nacional de educación básica que realizaron la Secretaría de Educación Pública (SEP) y el Instituto Nacional de Estadística, Geografía e Informática (INEGI), el 18\% del total de la planta docente del país son profesores de escuelas privadas (poco más de 400 mil), mientras que el 10\% de los alumnos ( 2 millones $600 \mathrm{mil}$ ) toma clases en colegios particulares. Esto significa que la proporción alumnos-docente es de 6 a 1, una cifra que resulta superior a la que presentan los países más desarrollados en el ámbito educativo como Noruega e Islandia, donde la proporción alumnos-docente es 9 a 1.

Si bien la estadística anterior no da cuenta de la calidad de la educación, sí nos permite afirmar que la posibilidad de interacción entre alumnos y docentes es amplia (contrario a lo que sucede en la educación pública, donde la proporción es 15 a 1 y, por ende, la posibilidad de interacción es reducida). Por otrolado, nuestro contexto social está determinado por el uso de las nuevas tecnologías de la información, lo que obliga a autoridades y docentes a explotar 
esta gran posibilidad de interacción implementando diversas herramientas de aprendizaje, como aquellas que involucran dispositivos electrónicos.

Entonces, el gran obstáculo al que se enfrenta la educación privada en México es un problema de mediatización, donde los nuevos dispositivos tecnológicos en lugar de reconfigurar el papel de docentes y alumnos en el proceso discursivo de aprendizaje, pareciera que lo han desconfigurado. De esta forma, el propósito del presente trabajo será explicar cuáles son las confrontaciones simbólicas entre alumnos y profesores a partir de la comprensión semiótica de los recursos digitales.

\section{EL RECURSO DIGITAL COMO METÁFORA DE LA INCLUSIÓN}

Si retomamos la concepción de metáfora de Paul Ricoeur (2001), ese lugar de continua tensión y transformación discursivas, podemos asumir que todo dispositivo que ingresa al campo de la cultura es una metáfora que tiende a concentrar tareas y funciones de dispositivos previos. Y claro, la novedad de estos dispositivos siempre produce inquietudes: "La tecnofobia camuflada de argumento cultural ha demostrado históricamente su corto recorrido, precisamente porque la cultura se alimenta de la tradición, pero también, y muy poderosamente, de la renovación" (Cordón, Gómez \& Alonso, 2011, p. 17).

La tendencia, entonces, indica que todo nuevo dispositivo termina por ser aceptado entre los usuarios. Esto significa que los recursos digitales que hoy son vistos con repulsión terminarán jugando un papel importante en la dinámica educativa. Pero por lo pronto, pensar en el recurso digital como una metáfora, nos conduce a una tensión y una transformación discursivas que deben ser analizadas. Retomar el concepto de metáfora que propone Ricoeur nos obliga al siguiente planteamiento: “ ¿Hacia dónde hay que leer ese movimiento, hacia un paradigma de reemplazos, o bien hacia una transformación, incluso una manipulación del sintagma en el que se inscribe, es decir, de su contexto discursivo?" (Pimentel, 2009, p. 10).

Ahora sustituyamos: ¿Hacia dónde hay que leer el movimiento de la digitalización del libro de texto, hacia un paradigma de reemplazos, o bien hacia una transformación, incluso una manipulación del sintagma en el que se inscribe, es decir, de su contexto discursivo? Pensar la digitalización del libro de texto como un reemplazo del libro impreso supone ir en contra de la historia de la cultura, la cual ha demostrado que cada nuevo dispositivo que se integra a las interacciones entre sujetos no sustituye a otros dispositivos existentes ni mucho menos a los mismos sujetos:

La aparición de todo nuevo soporte de comunicación ha representado siempre una redistribución de roles con respecto a los preexistentes, pero casi siempre desde la óptica de la coexistencia y no de la exclusión. Y con el libro electrónico ocurrirá algo parecido (Cordón et al., 2011, p. 17). 
En nuestros días seguimos usando un invento de hace 5 mil años para escribir: la tinta. La integración del libro de texto electrónico a la educación, y los recursos digitales que esto conlleva, supone una coexistencia con el libro de texto impreso, con el pizarrón, con el globo terráqueo, con los esquemas del cuerpo humano hechos de madera o de plástico, pero, sobre todo, con el docente. Ahora, la problemática con ese afán inclusivo de los nuevos soportes de comunicación es que aumenta la cantidad y calidad de mediatizaciones. En el caso del libro de texto electrónico se pueden concentrar el libro de texto impreso, diccionarios, el pizarrón, el globo terráqueo, los esquemas del cuerpo humano y otras tantas herramientas didácticas.

Esta concentración implica que los docentes y alumnos desarrollen interacciones diversas, pero sin que haya cambios en sus tareas primigenias: los primeros seguirán siendo guías que orienten y faciliten la comprensión de todo el entramado escolar, desde los contenidos educativos hasta los soportes o dispositivos involucrados, así como las mediatizaciones derivadas, mientras que los segundos deben seguir desarrollando sus habilidades de aprendizaje: "El docente no sólo debe usar la tecnología para transmitir información, es necesario establecer actividades para formar en sus alumnos procesos de reflexión (...) como parte del proceso de madurez de sus percepciones" (Bivort, 2011, p. 92).

Facilitar la comprensión del conocimiento debe ser el antídoto de los docentes contra la tecnofobia. Vale la pena reflexionar en torno a que, sin importar qué tan avanzado sea un dispositivo electrónico o un recurso digital, el diálogo del profesor con el estudiante siempre será fundamental para facilitar esa comprensión:

El filósofo John Searle argumentó que la verdadera comprensión nunca se podrá conseguir a través de un programa de ordenador, no importaba cuán inteligente este fuera, ya que todo programa seguía únicamente reglas y por consiguiente nunca podría comprender lo que estaba haciendo (Turkle, 1995, p. 108).

Desde esta perspectiva, la concentración mediática del libro de texto electrónico hace que las interacciones entre profesores, alumnos y dispositivos electrónicos tengan una gran complejidad.

\section{SEDUCCIÓN Y DIÁLOGO CON EL DISPOSITIVO ELECTRÓNICO}

Pero antes de estudiar dichas interacciones, es importante subrayar quiénes son los sujetos que interactúan con el dispositivo electrónico: "El poder omnisciente del ordenador es un fenómeno al que frecuentemente nos referimos en términos de asociarlo a una adicción a las drogas. Llama la atención que la palabra usuario se asocie principalmente con los ordenadores y las drogas" (Turkle, 1995, p. 40). 
Pero más que adicción, la relación entre usuarios y dispositivos electrónicos es de seducción, ya que las interacciones producidas entre estos despliegan un conjunto de sentimientos y razonamientos, como si se estuviera con alguien más. Esa "compañía" esla denosotros mismos, de manera que el dispositivo electrónico funciona como un espejo que refleja una relación de seducción entre yo y alter:

Igual que los instrumentos musicales pueden ser extensiones de la construcción del sonido por parte de la mente, los ordenadores pueden ser extensiones de la construcción del pensamiento por parte de la mente. (...) Las personas se pueden ver a sí mismas en el ordenador. La máquina puede parecer un segundo yo (Turkle, 1995, p. 41).

En esta relación de seducción, el usuario establece un diálogo con su pensamiento a partir del dispositivo electrónico:

Con los nuevos medios electrónicos, el consumo pasivo de un texto o de una obra de arteseha acabado: ya no sólo mirola pantalla, sino que interactúo cada vez más con ella, entablando con la misma una relación de diálogo (Zizek, 2010, p. 134).

A lo que Turkle agrega que "la muestra dinámica y por capas me da la sensación reconfortante de que escribo en conversación con mi ordenador. Después de dichos encuentros, un pedazo de papel en blanco puede hacerme sentir extrañamente sola" (1995, p. 40).

Hemos visto, entonces, cuál es la trascendencia del usuario. Si asumimos que el alumno se desarrollará como tal, entonces necesitamos analizar cómo selleva a cabo ese diálogo con su pensamiento. Las interacciones resultantes de este proceso dialógico le otorgarán al docente fundamentos para comprender las dinámicas de aprendizaje del alumno y para crear y desarrollar un aparato didáctico que le permita integrar el libro de texto electrónico a su entramado educativo.

La gran disyuntiva es, ahora, ¿cuál es o debe ser el rol del docente en torno a los dispositivos electrónicos? Antes que profesor, debe asumirse también como usuario:

El ordenador es todavía una herramienta que se parece menos a un martillo y más a un clavicémbalo. No aprendes cómo se toca un clavicémbalo asimilando inicialmente un conjunto de reglas, de la misma forma que no aprendes sobre un micromundo simulado, ya sea una interfaz gráfica tipo Macintosh o un videojuego, ahondando en un manual de instrucciones. En general, aprendes a través de una exploración ociosa (Turkle, 1995, p. 79).

Alumnos y docentes (usuarios) aprenderán a utilizar los dispositivos electrónicos y los recursos digitales que estos contengan (incluido el libro de texto) solo a través de una exploración ociosa y, casi siempre, personal. Aunque los profesores reciban capacitaciones para navegar sobre un recurso del libro de texto digital, 
solo a través de la libre exploración, de apretar botones, de abrir hipervínculos, de probar opciones de menús, de jugar, escribir y dibujar, de prender y de apagar, será como dominen e integren estos soportes a su contexto cultural y educativo.

\section{LA INCUBACIÓN DEL VERDUGO}

Al inicio del artículo describimos cómo es que los docentes de las escuelas secundarias de México no usaban los recursos digitales brindados por una empresa editorial debido a su tecnofobia. Dichos recursos derivan de la digitalización del libro de texto. Esto es, diversos contenidos de las asignaturas que comprenden los programas de educación secundaria son abordados a partir de una serie de recursos digitales que tienen ciertas características y cumplen determinadas funciones.

Si bien cada casa editorial interpreta y crea los recursos digitales que cree pertinentes a partir de sus libros de texto y de los programas oficiales de la Secretaría de Educación Pública, lo cierto es que estos recursos presentan características comunes. Primero, los contenidos digitales delas diversas asignaturas son consultados exclusivamente a través de dispositivos electrónicos, pueden ser computadoras o tabletas. Y segundo, estos contenidos se desarrollan a partir de una secuencia didáctica interactiva, la cual consiste en una serie de acciones que ordenan y guían el proceso de enseñanza.

Una secuencia didáctica está compuesta por tres momentos: una apertura, donde se identifican y recuperan saberes, conocimientos previos y preconcepciones, se contextualiza el tema y se plantean situaciones problemáticas; un desarrollo, donde se relacionan los saberes, los conocimientos previos y las preconcepciones para definir las áreas del conocimiento y las habilidades que se involucrarán: se construyen, individual y colaborativamente, nuevos conceptos, al tiempo que se refuerzan habilidades y actitudes; $y$ un cierre, en el que se relacionan los aprendizajes adquiridos con otras áreas. Se llevan a cabo actividades de aplicación, publicación de resultados y análisis de proceso. Se evalúa cualitativa y cuantitativamente (Sistema Uno Internacional, 2015).

Para reforzar y amenizar una secuencia didáctica, se pueden insertar elementos lúdicos en el desarrollo y el cierre de la misma como crucigramas, dibujos, juegos de memoria, entre otros. Antes de la irrupción de las nuevas tecnologías en la educación, el medio o el dispositivo por excelencia que permitía la relación discursiva entre la secuencia didáctica y el educando era el libro de texto impreso. A partir de este medio los docentes de educación básica en México se formaron como estudiantes y profesionales de la educación; asimismo, han desarrollado su ejercicio magisterial en torno a este dispositivo.

En ese sentido, las secuencias didácticas aprovecharon las bondades del libro impreso para explotar su aspecto lúdico: invitar a los educandos a dibujar, colorear, recortar y pegar imágenes y textos. Pero ahora los recursos digitales 
obedecen a otra lógica de interacción: en lugar de dibujar, recortar y pegar imágenes y textos de los libros impresos, los alumnos dan clics y tocan la pantalla para activar botones y arrastrar elementos.

Con base en el principio de inclusividad de los soportes de comunicación, podemos afirmar que todas estas actividades escolares (dibujar, recortar, pegar, dar clics, tocar pantallas) son juegos que los estudiantes pueden practicar de manera indiscriminada, es decir, el surgimiento de recursos digitales no va en detrimento del dibujo o del recorte de figuras eimágenes. Concebir la secuencia didáctica como un juego, independientemente del dispositivo que la soporte, es un análisis que debemos realizar en aras de que el docente comprenda que, antes que la tecnología, la clave para entender cómo se desarrolla cualquier tipo de interacción didáctica está en el lenguaje.

\section{LA SECUENCIA DIDÁCTICA COMO REPRESENTACIÓN DEL JUEGO}

Cualquier texto puede ser un juego, ya sea de forma literal o metafórica. Un ejemplo de la perspectiva lúdica del lenguaje radica en la poesía y en la retórica, donde se analizan y construyen rimas, juegos de palabras, anagramas, acrósticos, palíndromos y hasta lenguas inventadas por un autor determinado. No obstante, en estos juegos textuales prácticamente solo hay una forma de interacción: el autor utiliza el lenguaje según su ingenio, él es el jugador y el lenguaje su juguete, por lo tanto, el lector solo es un espectador, así que no puede participar en el juego.

Desde esta perspectiva, si los alumnos actúan como lectores, entonces no pueden participar en los juegos textuales mencionados. Pero hay otra estrategia textual que sí permite una interacción lúdica entre profesores, alumnos y secuencias didácticas:

Otra manera bastante literal de convertir el texto en un juego es plantear un problema al lector. En juegos como las adivinanzas, los trabalenguas, los crucigramas e incluso las novelas de misterio, tanto el lector como el escritor participan como jugadores (Ryan, 2004, p. 218).

Entonces, una secuencia didáctica puede ser lúdica si incluye juegos como anagramas, acrósticos y palíndromos, pero también trabalenguas, crucigramas, adivinanzas y problemas para resolver; la diferencia es que este último grupo de textos provee una mayor interactividad porque invita al alumno a convertirse en un jugador:

Un buen juego consiste en un diseño global que garantice una participación activa y placentera del jugador en el mundo del juego (el término mundo no significa aquí la suma de objetos imaginados, sino que se refiere al espacio y al tiempo delimitados en los que tiene lugar la acción, en un sentido no figurado) (Ryan, 2004, p. 220). 
Cuando los textos no son juegos, su forma está supeditada al contenido. La estructura y organización del texto, es decir, su esqueleto, depende de lo que determine dicho contenido. En cambio, "en el texto como juego, la forma es el equivalente de un exoesqueleto: en vez de subordinar la forma al contenido, el contenido se considera el relleno de la forma" (Ryan, 2004, p. 235). En una secuencia didáctica tendrán lugar textos lúdicos y no lúdicos. Hemos visto que algunos textoslúdicos pueden ejercer un alto grado de interactividad. En el caso delos textos nolúdicos, aun cuando su contenido no representela resolución de un desafío para el alumno-lector, la forma o la presentación del texto es determinante para ejercer un cierto grado de interactividad, tanto en un dispositivo tradicional (libro impreso), como en uno electrónico (recurso digital).

Más adelante revisaremos algunas estrategias editoriales que sustentan la premisa establecida sobre la interactividad del texto; por lo pronto, es importante argumentar por quéla tecnología no determina, en un primer momento, esa interactividad:

Tendemos a pensar que es la tecnología informática la que ha hecho posible el fenómeno de la interactividad, pero ésta es en realidad una dimensión de la interacción cara a cara que quedó excluida con la aparición del manuscrito y la escritura impresa y que el medio electrónico ha reintroducido en los mensajes escritos (...) como el intercambio en tiempo real (sincrónico) (Ryan, 2004, p. 247).

Podríamos decir que la interactividad está dada, primero, por el propio texto y, después, por el dispositivo que lo entrega:

\footnotetext{
La interactividad aparece en dos niveles: uno lo constituye el medio o soporte tecnológico, el otro es intrínseco a la propia obra. Todos los mundos interactivos requieren un medio razonablemente interactivo, pero no ocurre lo mismo al revés. (...) Internet en su conjunto es un medio interactivo, pero muchos de los documentos que están disponibles en la red son textos lineales clásicos (Ryan, 2004, p. 249).
}

Por otro lado, es conveniente identificar que los dispositivos electrónicos poseen una naturaleza lúdica. De acuerdo con Turkle (1995), estas son algunas cualidades estéticas del ordenador: "preferencia de la superficie por encima de la profundidad, de la simulación por encima de lo real, del juego por encima de la seriedad" (1995, p. 58). Los dispositivos electrónicos u ordenadores se han convertido en portadores de nuevas formas de conocimiento, lo que implica hacer un "nuevo énfasis en la visualización y en el desarrollo de la intuición a través dela manipulación de los objetos virtuales" (1995,p.68).Lainformación creada para su consulta o consumo desde dispositivos electrónicos, como es el caso de los recursos digitales, estará delimitada por la preferencia de la superficie, de la simulación y del juego. 
De manera que tendremos secuencias didácticas donde se ponderará el texto breve y conciso que invite a la reflexión del alumno en lugar del texto largo que desarrolla diversas ideas y presenta diferentes perspectivas sobre un tema (como lo hace el libro de texto impreso), lo que deriva no solo en una invitación, sino que se convierte en una orientación de la reflexión del alumno. Asimismo, las secuencias didácticas de los recursos digitales trabajarán sobre escenarios virtuales de investigación y práctica (simulación); donde, por ejemplo, se sustituye el laboratorio de química tradicional por uno virtual en el que se mostrarán los efectos de combinar determinados elementos o compuestos a partir del arrastre de imágenes o animaciones de tubos de ensayo o de matrices con el ratón del ordenador. Explicada la preferencia dela superficie y de la simulación, sólo nos resta aterrizar la noción del juego en los recursos digitales, pero antes de hacerlo es necesario reparar en que, tanto los recursos digitales como los juegos, son metáforas.

\section{EL FUNCIONAMIENTO DEL RECURSO DIGITAL COMO METÁFORA}

Hasta el momento, hemos recorrido dos aduanas fundamentales para entender la tensión discursiva de la digitalización del libro de texto: pensar el recurso digital como una metáfora concentradora y la posibilidad lúdica de dicha metáfora. Es importante retomar una y otra vez las propiedades de la metáfora para entender la composición y el funcionamiento del recurso digital:

La fuerza metafórica requiere una combinación de novedad y oportunidad, de lo extraño y lo evidente. La buena metáfora nos satisface a la vez que nos sorprende. La metáfora será más potente cuando el esquema transferido genere una organización nueva y notable, en lugar de limitarse al reetiquetado de una antigua (Genette, 1997, p. 82).

El recurso digital presenta una organización nueva, distinta del libro de texto impreso, y justo a partir de dicha organización convertirá en juegos todos aquellos textos que naturalmente no son lúdicos.

En líneas anteriores decíamos que aunque un texto no sea lúdico existen diversas estrategias editoriales, tanto en dispositivos tradicionales como electrónicos, para lograr que dicho texto sostenga un importante grado de interactividad con el alumno. En libros impresos la estrategia más común es la inclusión de material recortable, el cual puede desprenderse del dispositivo y utilizarse de acuerdo con las instrucciones que alguna actividad de la secuencia didáctica demande.

Pero también existen otras estrategias, las cuales, además, no solo son propias del libro de texto, sino que se han extendido a campos como la literatura, para tratar de refrescar y revolucionar la narrativa, principalmente la infantil 
y juvenil. Ahora también se pueden incluir cartas, pequeñas libretas, lápices, tarjetas, pines, posters, figuras, juegos y demás objetos que puedan reproducirse a través de una impresora.

En el caso de los dispositivos electrónicos, en lugar de estrategias editoriales tenemos una organización discursiva que permite convertir un texto no lúdico en uno altamente interactivo. Esta organización está basada en el clic y el arrastre, los cuales se realizan con el ratón de un ordenador o, en el caso de dispositivos electrónicos táctiles, con los dedos. Los equipos editoriales desarrollan secuencias didácticas en los recursos digitales donde la información no está dada "por completo", como pudiera ocurrir con un libro impreso. En ese contexto, el estudiante tiene que dar un clic por aquí o por allá y arrastrar elementos de un lugar a otro para abrir nuevas ventanas de información y completar el discurso del aprendizaje.

Ahora bien, para entender la organización del recurso digital debemos tomar en cuenta que la metáfora está organizada por dos grandes partes, las cuales operan de la siguiente manera: "En resumen, si $a$ expresa $b$ entonces 1 ) $a$ posee $b$, o es denotado por $b ; 2)$ esta posesión o denotación es metafórica; y 3) $a$ refiere a $b$ " (Goodman, 2010, p. 94). Es importante entender cómo es que $a$ expresa $b$. Para ello, habría que distinguir entre representación y expresión: "Una característica provisional entre representación y expresión es que la representación lo es de objetos o acontecimientos, mientras que la expresión lo es de sentimientos u otras propiedades" (Goodman, 2010, p. 54).

Queda de manifiesto, entonces, que en una metáfora $a$ representa un objeto o acontecimiento de $b$, pero además transporta una carga de sentimientos propios de dichos acontecimientos. La representación se presenta en un primer plano de la metáfora:

Lo que hemos hecho hasta ahora es subsumir la representación, junto con la descripción, en la denotación. Esto nos ha permitido (reconocer la representación) como una relación simbólica y variable. De esta manera, la representación se diferencia de los modos no denotativos de referencia (Goodman, 2010, p. 52).

Para representar un objeto hay que describirlo y al hacerlo se hace referencia a lo que se representa: "La referencia a un objeto es una condición necesaria para figurarlo y describirlo, pero ningún grado de semejanza es condición necesaria o suficiente para ello" (Goodman, 2010, p. 50). Para entender esta dualidad entre representación y expresión, con adverbios, Goodman (2010) hace un par de analogías; representación es a literalmente, mientras que expresión es a metafóricamente: "Lo que expresa ejemplifica metafóricamente. Así, lo que expresa tristeza es metafóricamente triste, pero no literalmente triste, es decir, se incluye bajo la aplicación transferida de una etiqueta coextensiva con triste" (2010, p. 87). 
Entonces, si en la metáfora $a$ expresa $b$, debemos definir quién es $a$ y quién $b$. Decíamos que el programa informático anexa todo un conjunto de datos al recurso digital. La totalidad de este conjunto puede considerarse como $b$. A partir del clic y del arrastre, la organización discursiva propia del dispositivo electrónico, será posible dilucidar cada una de las partes del conjunto de datos precargados al recurso digital o, dicho en términos de Goodman, que $a$ (el clic y el arrastre) exprese $b$ (toda la información del recurso digital). Tenemos ahora un aspecto interesantísimo: la forma en que los clics y arrastres expresen la información del recurso depende estrictamente del usuario, en este caso, el estudiante.

Con todas sus capacidades intelectuales y emocionales, el estudiante decidirá qué información expresará, de manera que habrá información que quede oculta o que sea deliberadamente ignorada. El libro impreso y el recurso digital son dos sistemas semióticos que se activan de diferentes formas. El primero obliga a la lectura del texto para producir semiosis, en tanto que en el segundo dicha semiosis está condicionada, primero, por la elección de hipervínculos y después por la lectura:

El texto electrónico es el producto de un sistema semiótico de dos niveles, por medio del cual los signos que se envían a la pantalla son el resultado de un programa informático. Aunque los signos de este programa permanecen invisibles, regulan el flujo de palabras, determinan su apariencia, y de manera más general controlan su coreografía (Ryan, 2004, p. 259).

Este ocultamiento de la información determina que la interactividad esté más plenamente desarrollada en un entorno electrónico que en uno impreso:

En un entorno electrónico el lector no va al texto, sino que el texto va a la pantalla. (...) Con un texto impreso el lector tiene que realizar un "movimiento hacia" - su objetivo puede ser una página de un libro, una estantería de la biblioteca o una tienda de la ciudad-, para obtener nuevos materiales, pero con los textos electrónicos todo lo que tiene que hacer el lector es clic en el enlace (Ryan, 2004, p. 258).

Las partes de una secuencia didáctica conforman una estructura. En el libro impreso esa estructura es más rígida que en el recurso digital, es decir, si en el primero se omite una de las partes de la estructura de una secuencia didáctica, resulta más probable que las significaciones de esa estructura pierdan sentido:

Un texto lineal clásico funciona de acuerdo con un protocolo de sucesión conocido como cola. Es decir, que el lector debe terminar cada unidad antes de avanzar hasta la siguiente (...). Con la posibilidad de colocar hiperenlaces en cualquier punto, el texto electrónico (es una) invitación abierta a recorrer caminos secundarios, una estrategia conocida como "navegar" (Ryan, 2004, p. 262). 
Debido a esta "navegación por caminos secundarios", puede decirse que las partes del recurso digital son más "independientes": su estructura pierde menos sentido si no es develada en su totalidad y cada una de las partes actúa como un subsistema de signos con una significación determinada:

Si tal como lo han proclamado varios teóricos, los textos electrónicos "reconfiguran" la noción de autor, no es fundiendo la escritura y la lectura en un sólo acto como lo hacen, sino añadiendo la dimensión del diseño a la producción del texto (Ryan, 2004, p. 259).

Esa autonomía que caracteriza a las partes de una secuencia didáctica está dada, en buena medida, por el diseño y la programación del recurso digital. En el caso del diseño, el alumno identificará cuáles son los límites de un subsistema $A$, por ejemplo, porque el estilo y el color de botones, recuadros de texto y otros elementos visuales guardarán cierta uniformidad. Así, los demás subsistemas ( $B, C, D$, etc.), serán diferentes visualmente entre sí.

En el caso de la programación, el alumno puede desplazarse a lo largo y ancho de un recurso digital sin un orden completamente establecido:

Ellector curiosea entre los enlaces, echa una ojeada a los productos que ofrecen las pantallas y, o bien los compra, o bien se marcha a otra pantalla. Este lector no siente la obligación de leer el texto completo o de prestar atención a todas las pantallas, porque no contempla el texto como un mundo cuya unidad se mantiene gracias a un diseño global, sino como un surtido de recursos entre los que puede escoger los que le apetezcan libremente (Ryan, 2004, p. 264).

Pero cuando el alumno se encuentre en un subsistema de la secuencia, si pretende dilucidar el sentido de este conjunto de signos, sí estará obligado a navegar el recurso con el orden que editores y programadores han establecido. Es decir, el alumno no podrá pasar de $x$ a $z$ si antes no pasa por $y$. De esta manera, diseño y programación delimitarán las significaciones de los subsistemas de signos que conformarán la secuencia didáctica del recurso digital.

Tanto en los dispositivos tradicionales como en los electrónicos, pareciera que la secuencia didáctica es vista como un gran rompecabezas, donde el alumno busca y encuentra las partes faltantes y las acomoda para dar sentido a este discurso del aprendizaje. Pero entonces, ¿qué no estas estrategias terminan por convertir un texto no lúdico en un texto lúdico? ¿ Ha sido, es y seguirá siendo el juego el mejor camino para vincular la triada editorial del aprendizaje (profesores, textos y alumnos)? Para poder responder estas interrogantes primero hay que contestar otras preguntas trascendentales. Si el recurso digital empodera al estudianteyle permite elegir quéinformación consultar o revelar para construir su discurso de aprendizaje, ¿qué elemento(s) interviene(n) en la elección del estudiante para revelar tal o cuál información? ¿Qué determina que el alumno elija el botón $K$ o el enlace $P$ en lugar del botón $J$ o el enlace $Q$ ? 


\section{LA INTENCIONALIDAD EN LA ELECCIÓN DE HIPERVÍNCULOS}

Franz Brentano (1992), quien retoma el concepto de intencionalidad en la filosofía moderna, afirma que ésta es una capacidad inherente al pensamiento y a la conciencia humana. Para él, la intencionalidad refiere a un contenido, a un objeto, a "algo". Para comprender ese "algo", Brentano dice "que nos alegramos de algo por algo, que nos entristecemos o apesadumbramos por algo; y también se dice: esto me alegra, esto me duele" (1992, p. 84).

La intención es propia de los fenómenos psíquicos o mentales, y permite entender al objeto: "podemos definir los fenómenos psíquicos diciendo que son aquellos fenómenos que contienen en sí, intencionalmente, un objeto" (Brentano, 1992, p. 82), esto es, existe una relación que se da entre un sujeto mentalmente activo y un objeto presente en su conciencia; esa relación es de carácter inherentemente intencional y comprende experiencias, creencias, deseos y sensaciones que estarán puestas en relación con el objeto.

La intencionalidad es un atributo de los objetos de la conciencia. Brentano denomina como objeto intencional aquel movimiento de la conciencia que se traduce en acto: "el objeto intencional no es real en la conciencia, pues lo único real es el acto, y la única forma en que puede estar dado en éste es justamente como objeto, o sea, como correlato intencional" (1992, pp. 124 y 125). Puede decirse, entonces, que Brentano sugiere, en principio, que todo acto es intencional.

Retomamos los fundamentos de la intencionalidad que postuló Brentano para tratar de comprender por qué el estudiante hace clic en $C$ en lugar de hacerlo en $D$, y encontramos algunas particularidades: si la intencionalidad es una capacidad inherente al pensamiento y manifiesta una relación entre un sujeto (el alumno) y un objeto presente en su conciencia (el recurso digital), entonces existe una intencionalidad que determina los subsistemas de signos que el estudiante elige cuando navega a través de una secuencia didáctica. Si todo acto es intencional, entonces cada clic y cada arrastre es motivado por "algo".

De acuerdo con Searle (1983), quien retoma el trabajo de Brentano, afirma que "la intencionalidad es aquella propiedad de muchos estados mentales por los cuales éstos se enfocan o se refieren a objetos y estados de atracciones en el mundo" (p. 14). Para clarificar está premisa, Searle asegura que "intencionalidad no es lo mismo que conciencia. Muchos estados conscientes no son intencionales (...) y muchos estados intencionales no son conscientes" (p. 15). Searle manifiesta que no todos los estados mentales tienen intencionalidad; que las creencias, miedos, esperanzas y deseos son intencionales, pero que hay formas de nerviosismo y ansiedad indirecta que no son intencionales. 
Para Searle no hay ninguna acción sin intención, a pesar de que hay muchos aspectos incomprensibles en alguna acción:

\begin{abstract}
Pero hay que darse cuenta que, mientras hay muchos estados de atracciones que no son pensados para obtener o desear obtener algo, no hay acciones sin intenciones. Aún en una acción que pareciera no intencional como el casamiento de Edipo con su madre, este suceso significa una acción idéntica que Edipo provocó intencionalmente, esto es, casarse con Yocasta. Hay muchos estados de atracciones sin queles correspondan creencias, y muchos estados de atracciones sin deseos que les correspondan, pero en general no hay acciones sin intenciones que les correspondan (1983, p. 82).
\end{abstract}

Searle concibe una acción como todo lo que uno puede provocar. Por ejemplo, estornudar no puede considerarse una acción porque no es algo que nosotros provoquemos, pero sí lo es beber, abrazar, leer, hablar y, claro, elegir. Es decir, cada clic es una elección, por lo tanto, es una acción. Ahora, un rasgo distintivo de la intencionalidad es que siempre está siendo comunicada, ya sea a base de acciones o de palabras:

Una declaración está satisfecha si y solo si es verdad, una orden está satisfecha si y solo si es obedecida, una promesa está satisfecha si y solo si es cumplida, y todo esto también aplica a los estados intencionales. Las creencias están satisfechas si las cosas son como yo las creo, los deseos están satisfechos si son cumplidos, las intenciones están satisfechas si son comunicadas (Searle, 1983, p. 100).

De manera que, para Searle, todo acto conlleva una intención. Así, nadie puede hacer una declaración sin expresar una creencia o hacer una promesa sin expresar una intención porque la condición esencial del acto del habla tiene, como condiciones de satisfacción, las mismas condiciones de satisfacción que las que expresan los estados intencionales. Entonces, en esta lógica, una elección virtual es satisfecha, en términos de Searle, si y solo si la información presentada al estudiante tiene ciertas características. Ahora, si el estudiante se engancha con alguna de estas características, puede continuar una navegación deliberada por ese subsistema de signos y apropiarse de información que le permita construir su discurso de aprendizaje. De lo contrario, elegirá salir de ese subsistema y empezar la navegación en otro.

Dennet (1998) también manifiesta que todo lo que se dice tiene una intención de por medio: "Para obtener lo que se quiere a menudo hay que decirlo (...) ¿La gente utiliza de verdad esta estrategia (intencional)? Sí, siempre” (1998, pp. 31 y 32). Adjudica a la intencionalidad, la cual afirma que se manifiesta como una actitud o estrategia, una habilidad predictiva: "La estrategia intencional nos brinda un poder predictivo que no podemos obtener por ningún otro método" (1998, p. 33). Para Dennet, cualquier estrategia tiene el objetivo de predecir el comportamiento de un objeto o sistema. De hecho, retoma a Bren- 
tano y asegura que "la estrategia intencional consiste en tratar al objeto cuyo comportamiento se quiere predecir como un agente racional con creencias y deseos" (1998, p. 27). Puede concluirse que el encontrar la significación de las partes de una secuencia didáctica también implica develar su intencionalidad: "Si yo digo algo como John cree quep, el enunciado se puede entender por sísolo. Pero si yo digo que John quiso decir que p, el enunciado sugiere una reflexión (para entender lo que $p$ quiso decir)" (Searle, 1983, p. 106).

¿Cuál es la estrategia intencional del estudiante con respecto al recurso digital? Si el dispositivo electrónico representa esta alteridad mental, este espejo en el que se ve reflejado el alumno, entonces espera que el recurso digital responda conforme a su racionalidad, a sus creencias y a sus deseos. Todo este compendio de características intelectuales y emotivas se pueden traducir en una sola situación: el juego. La estrategia intencional del recurso digital es el juego. El estudiante busca, por medio del juego, entender lo que la secuencia didáctica quiso decir.

\section{HACIA UNA NUEVA NARRATIVA DIDÁCTICA}

Volviendo al planteamiento inicial, si se concibe al recurso digital como una metáfora, también es posible explicar cómo a través de las significaciones de dicha metáfora se establecen los razonamientos que permiten alos estudiantesla construcción de un discurso propio de aprendizaje: "Como proceso retórico de significación, la metáfora, de manera más evidente que los demás tropos, abarca simultáneamente los niveles más abstractos y los más concretos del lenguaje en un solo acto de significación" (Pimentel, 2009, p. 25). Revisemos cómo se relaciona lo concreto y lo abstracto con los dispositivos tradicionales y electrónicos.

Nos encontramos ante dos procesos cognitivos: pareciera que la relación libro de texto-estudiante va de lo abstracto a lo concreto, y que la relación recurso digital-estudiante va de lo concreto a lo abstracto. Quizás la preferencia de un educando por un dispositivo electrónico en lugar de uno tradicional se deba a que su forma de aprender se relaciona más con el proceso cognitivo que ofrece el primero. Levi Strauss y Jean Piaget descubrieron y evidenciaron que el razonamiento de los niños empezaba con objetos y avanzaba hacia la teoría, es decir, iba de lo concreto a lo abstracto. Piaget observó que los niños tienen una organización concreta y que, para entender conceptos abstractos como número, primero tienen manipular objetos, es decir, para entender el significado de un signo, primero deben tener un contacto con su referente en la realidad: "En nuestra cultura, la división entre lo abstracto y lo concreto no es una simple frontera de proposiciones y objetos sino una manera de separar lo limpio de lo sucio, la virtud del tabú" (Turkle, 1995, p. 72).

El razonamiento adulto es distinto: va de lo abstracto a lo concreto. No hay que olvidar que nuestro planteamiento inicial aborda una problemática de es- 
tudiantes de secundaria, es decir, que empiezan a ser adolescentes, por lo tanto, se encuentran en una encrucijada: continuar con el tipo de razonamiento que han cultivado desde la infancia o practicar este nuevo razonamiento que nace de sus incipientes abstracciones:

Desde la mirada del niño, el ordenador, reactivo e interactivo, es un objeto en los límites de la vida. De esta forma, los ordenadores son para los niños objetos evocadores, que les hacen encontrar nuevas razones sobre qué hace que las cosas estén vivas y qué hay de especial en ser una persona (Turkle, 1995, p. 98).

Como se mencionó en párrafos anteriores, los estudiantes adolescentes (usuarios) encuentran en el dispositivo electrónico un medio de relación dialógica. Las interacciones que desarrollan con un programa informático les permiten construir una historia:

\begin{abstract}
A los niños les atraía pensar psicológicamente en el ordenador por dos razones: primera, el ordenador era responsivo; actuaba como si tuviese una mente. (...) Para los niños, como para los adultos, los objetos informáticos interactivos y opacos provocaban pensamientos que viraban hacia otro famoso objeto interactivo y opaco: la mente humana (Turkle, 1995, p. 102).
\end{abstract}

Por otro lado, pensemos nuevamente en el recurso digital como metáfora pero, sobre todo, en las propiedades de esta última: "La metáfora se presenta entonces como una estrategia de discurso que, al preservar y desarrollar el poder creativo dellenguaje, preserva y desarrolla el poder heurístico desplegado por la ficción" (Ricoeur, 2001, p. 12). El recurso digital es una metáfora porque genera una tensión discursiva a partir de la confrontación de dos mentes humanas, una que pertenece al estudiante y una virtual. Ambas "mentes" tienen ese poder creativo del lenguaje que, a su vez, puede desplegar la construcción de una ficción: "La metáfora es el proceso retórico por el que el discurso libera el poder que tienen ciertas ficciones de redescribir la realidad" (Ricoeur, 2001, p. 13).

El recurso digital, entonces, es una metáfora capaz de proporcionar las "ficciones" necesarias para que el estudiante redescriba la realidad. Entonces, si visualizamos el discurso del aprendizaje como una narrativa, necesitamos a un narrador, que en este caso puede encontrarse en el libro de texto impreso, y a un lector o espectador, que puede ser el alumno. Pero con la irrupción de los recursos digitales, este modelo narrativo sufre una reconfiguración:

\footnotetext{
Buena parte de las estrategias narrativas que habitualmente eran atribuidas a un sujeto narrador que está dentro de la diégesis ahora son asumidas por dos sujetos simultáneamente: el interactor, un sujeto yo que se deja sumergir en la simulación, que hace que se desencadenen los acontecimientos de la diégesis y, por el otro, un sujeto-SE, un programa de generación automática de situaciones narrativas que dialoga con el primero (Machado, 2009, p. 132).
} 
En la narrativa didáctica tradicional, el libro de texto cuenta la historia, mientras que en la narrativa didáctica electrónica, los estudiantes y la interfaz delordenador construyenla historia. Se rompe el esquema del narradoromnisciente que sabe qué va a pasar en todo momento y que controla los personajes y toda la trama de la historia:

A este programa no le corresponde decidir concretamente qué va a suceder (ya que eso también depende de las decisiones tomadas por el interactor), pero sí le corresponde establecer el universo de eventos permitidos y las condiciones para que éstos sucedan (Machado, 2009, p. 132).

En los recursos digitales se establece un juego que consiste en revelar información que está oculta. Dentro de esta lógica, el jugador-estudiante puede omitir información deliberadamente. Anteriormente mencionábamos que el alumno puede "pasearse" por un recurso digital, ingresar a una serie de pantallas (susbsistemas de signos)y, sile interesaban, continuar la navegación respetando el orden impuesto por editores y programadores. De lo contrario, podría salir de esa pantalla y dirigirse a otra e involucrarse en otro subsistema de signos:

\footnotetext{
En términos generales se suele señalar como marca diferencial de los medios digitales, la interactividad, o más exactamente, el gerenciamiento del espectador: desde el primer momento todo lo que sucede en la pantalla depende de las decisiones, las acciones y las iniciativas tomadas por el sujeto que se relaciona con ella (Machado, 2009, p. 131).
}

Lainteractividad digital implica que el estudiante decida cuál información "destapar" y cuál no: "Los lectores de un hipertexto han de tomar decisiones y actuar para avanzar en la lectura. El proceso de toma de decisiones (elección de enlaces) es interesante y revelador por sí mismo" (Pajares, 2004, p. 121). La importancia de que el profesor se asuma primero como usuario del recurso digital yluego como guía u orientador de su contenido, radica en que tiene que ser testigo de cómo el poder de decisión recae en un solo clic. Claro, si bien la tarea del profesor es revelar toda la información del recurso digital, también debe argumentar por qué se debe omitir cierta información de la secuencia, si así lo decide, y por qué se deben detener para enfatizar en determinado contenido.

Y en el caso del estudiante, este poder que tiene para elegir las partes que conformarán su discurso de aprendizaje provoca que se construyan diversas "historias", como si un fragmento de la realidad fuera explicado o contado por varios juglares, quienes ofrecen una amplia gama de perspectivas narrativas. Esta construcción de discursos diversos tiene singulares implicaciones en el aula:

No hay una respuesta correcta ni una solución única. No es suficiente con una respuesta automática o reproducida de alguna fuente. Se requiere que los 
estudiantes juzguen yvaloren el material. Se requiere originalidad, innovación, creatividad e interpretación personal a la hora de enfrentarse al material. El contenido está orientado principalmente a explorar la conceptualización de la asignatura (y no a memorizar contenido) (Pajares, 2004, p. 152).

Pero no hay que olvidar que la relación dialógica que establece el estudiante con el recurso digital se asemeja más a una relación introspectiva que a una relación con el otro. En términos de Bajtín, es una relación con ego y no con alter, donde el dispositivo electrónico funciona como un espejo y el recurso digital, continuando con esta metáfora, es la cantidad de luz que alumbra el autoconocimiento de ego.

La confrontación es el término clave que nos permite distinguir a una relación entre estudiante-recurso digital (ego-ego) yuna entre estudiante-profesor (ego-alter). Como se menciona en el título de este trabajo, las confrontaciones solo son posibles entre alumnos y profesores. La confrontación es el vínculo que une a ego y alter:

La influencia del otro sobre mí es, en un principio, favorable y benigna: el otro me otorga la primera definición de mí (...), el otro posee un excedente de visión sobremi persona y el mundo, al percibir todo aquello que yo no puedo ver desde mi posición única (Bubnova, 1996, p. 19).

En ese sentido, no hay ningún dispositivo educativo, llámese recurso digital o libro de texto impreso, que consiga que el estudiante domine por completo el contenido de un tema:

Los entornos virtuales no proporcionan la interacción necesaria para que en un proceso de aprendizaje se alcance el dominio máximo de destreza. Es decir, el nivel de habilidades adquiridas siempre será inferior al que es posible llegar en una interacción educativa presencial. El aprendizaje hunde sus raíces en dinámicas sociales y juegos de interacción que requieren contacto personal continuado entre discentes y docentes (Mozo, 2006, p. 54).

El aprendizaje consta de diversas etapas; primero, el estudiante aprende a seguir instrucciones que establece el docente para desarrollar tareas y actividades que deriven en el reconocimiento del aprendizaje. En la segunda etapa, el alumno afronta situaciones reales, trata de comprender lo más importante de un contexto, observa muchos ejemplos y establece premisas para explicar y orientar las acciones. En esta etapa "empieza un proceso de contextualización que permite al aprendiz comprender la significación dela información tratada" (Mozo, 2006, p. 55).

En la tercera etapa, el estudiante aprende a seleccionar rasgos importantes para tomar decisiones y tener un análisis de las situaciones; en este momento, 
el alumno busca imitar al profesor. En la cuarta etapa el estudiante es capaz de reflexionar y elaborar una teoría sobre su propio proceso de aprendizaje. En la quinta etapa, el estudiante se convierte en experto, es decir, que ha acumulado muchas experiencias de aprendizaje y puede discriminar entre situaciones concretas, formular problemas y definir su solución; pero para que se alcance este nivel, es necesaria la interacción presencial entre profesor y alumno:

Para convertirse en experto se requiere el apoyo personal del docente. (...) Cuando el aprendiz completa el estilo de su maestro con aportaciones, detalles y sutilezas propias, adquiere su propio estilo o voz y se convierte en un maestro, es el nivel de maestría (Mozo, 2006, p. 55).

De estas cinco etapas de aprendizaje, es posible que el alumno avance hasta la cuarta ponderando el apoyo de los recursos digitales sobre la orientación del profesor; no obstante, la última etapa de aprendizaje obliga a esta confrontación presencial entre alumno y docente, para intercambiar argumentos, ejemplos, metodologías:

En los entornos virtuales se pueden promover y alcanzar todas las etapas del proceso de aprendizaje descrito, con una excepción: la última. Resulta imposible convertirse en maestro en una interacción desarrollada en un espacio virtual. El estilo propio aparece cuando se pasa mucho tiempo cuerpo a cuerpo con diversos maestros" (Mozo, 2006, p. 55).

A pesar de que la educación se encuentra en los albores de una nueva narrativa didáctica, los protagonistas de la "historia" (alumnos y profesores) no han cambiado. Anteriormente, la narrativa fundamentada en el libro de texto impreso ponderaba la construcción de un discurso de aprendizaje por parte de los profesores. En esta nueva narrativa, la digitalización del libro de texto obliga a que alumnos y docentes trabajen en conjunto para la construcción de ese discurso de aprendizaje. Esto se debe a que el profesor debe asumirse primero como usuario, al igual que los alumnos, y después como el orientador y el facilitador del contenido.

Hilda, así como la mayor parte de los profesores de las escuelas privadas de México, deberán comprender que la digitalización del libro no es una desventaja docente, sino una oportunidad de incorporar nuevas estrategias didácticas a sus dinámicas escolares. Pero esa comprensión solo puede darse a partir de la interacción personal y sostenida con los recursos digitales. Únicamente de esta forma será posible que el profesor se involucre con el poder discursivo de la metáfora y adopte un nuevo entramado lúdico que fortalezca las interacciones en el aula, y que permita a los alumnos la construcción de un discurso de aprendizaje sólido y permanente. 


\section{DE TAREA... LAS CONCLUSIONES}

En las páginas anteriores se trató de ampliar los horizontes de comprensión de las confrontaciones simbólicas entre alumnos y profesores derivadas de la digitalización del libro de texto, y aunque se brindó un análisis semiótico muy general de esta problemática, nos es posible identificar hitos que, sin duda, deben desarrollarse en estudios posteriores.

Históricamente, nos encontramos en un punto de inflexión en la educación. La incorporación de recursos digitales equivale al momento en el que las universidades adoptaron el libro impreso a finales del siglo XV, o se usaron las radios comunitarias para alfabetizar personas en Latinoamérica a mediados del siglo pasado o se implementó el sistema de telesecundarias en México en la década de 1970. La lógica inclusiva de la cultura con los dispositivos técnicos nos obliga a pensar cuál será el punto de inflexión que determine la definitiva y mayoritaria incorporación de los recursos digitales y su relación con los demás dispositivos didácticos.

Entender el recurso digital como metáfora permite un análisis que va más allá del dispositivo electrónico y de la tecnología. De esta forma, se pondera el estudio del lenguaje y de los signos como la verdadera arena de tensión y discusión de la confrontación. Para el profesor es importante involucrarse en esta metáfora porque, como sujeto de enunciación, debe orientar la navegación de los alumnos en el recurso digital para que construyan un discurso de aprendizaje que, aunque sea selectivo y sintético, no deje de ser trascendental para el desarrollo cognitivo y educativo de los estudiantes.

Finalmente, habría que pensar en los distintos ámbitos de la cultura donde la interacción entre sujetos está dada de forma metafórica. Así como en la educación hemos visto que existe una metáfora del juego, es necesario considerar si existen metáforas (y sus implicaciones) en distintos ámbitos dela interacción social, en aras de enriquecer esa nueva filología que hace algunas décadas advirtió Clifford Geertz (1994) que cambiaría nuestra comprensión dela realidad y marcaría un parteaguas en la teoría social: "La analogía del texto, asumida en la actualidad por los científicos sociales, es, en ciertos aspectos, la más amplia de las recientes refiguraciones de la teoría social, la más audaz, y también la menos desarrollada" (1994, p. 44). 


\section{REFERENCIAS}

AA. VV. (2015). Escenarios digitales. DF, México: Sistema Uno Internacional.

Bivort, M. (2011). Enseñando a leer en Internet: pantalla y papel en las aulas. Buenos Aires: Aique.

Brentano, F. (1992). Psicología desde un punto de vista empírico. Madrid: Encuentro.

Bubnova, T. (1996). Bajtín en la encrucijada dialógica. En Iris Zavala (compiladora), Bajtín y sus apócrifos (pp. 13-72). Barcelona: Anthropos.

Cordón, J., Gómez, R. \& Alonso, J. (2011). Gutenberg 2.0: La revolución de los libros electrónicos. Gijón, España: Ediciones Trea.

Dennet, D. (1998). La actitud intencional. Barcelona: Gedisa.

Geertz, C. (1994). Conocimiento local. Ensayos sobre la interpretación de las culturas. Barcelona: Paidós.

Genette, G. (1997). La obra de arte. Madrid: Lumen.

Goodman, N. (2010). Los lenguajes del arte. Madrid: Paidós.

Goodman, N. (1990). Maneras de hacer mundos. Madrid: Visor.

Machado, A. (2009). El sujeto en pantalla. Barcelona: Gedisa.

Mozo, A. (2006). Sociabilidad en pantalla. Un estudio de la interacción en los entornos virtuales. Barcelona: Editorial UOC.

Pajares, S. (2004). Literatura digital, el paradigma hipertextual. Cáceres, España: Universidad de Extremadura.

Pimentel, L. (2009). La dimensión icónica de la metáfora. DF, México: UNAM.

Ricoeur, P. (2001). La metáfora viva. Madrid: Editorial Trotta.

Ryan, M. (2004). La narración como realidad virtual: La inmersión y la interactividad en la literatura y en los medios electrónicos. Barcelona: Paidós.

Turkle, S. (1995). La vida en la pantalla: La construcción de identidad en la era de Internet. Barcelona: Paidós.

Zizek, S. (2010). El acoso de las fantasías. DF, México: Siglo XXI. 


\section{IDENTIFICACION DEL AUTOR:}

Armando Monzón Nieves es Magister en Comunicación por la Universidad Nacional Autónoma de México (UNAM). Actualmente es docente en la Universidad Tecnológica Latinoamericana en Línea (UTEL) y se desempeña como editor de libros de textos impresos y digitales. Ha presentado y publicado diversos trabajos en el campo de la semiótica de la música, la cultura popular y la industria editorial.

\section{REGISTRO BIBLIOGRÁFICO:}

Monzón Nieves, A. (2016, diciembre). Digitalización del libro en México. Confrontaciones simbólicas entre alumnos y profesores. En InMediaciones de la Comunicación, 11, pp. 251-273. Revista dela Escuela deComunicación, Facultad de Comunicación y Diseño, Universidad ORT Uruguay, República Oriental del Uruguay. 